Chapter 2

\title{
Electrodeposition of $\mathrm{WO}_{3}$ Nanoparticles for Sensing Applications
}

\author{
L. Santos, J. P. Neto, A. Crespo, P. Baião, P. Barquinha, L. Pereira, \\ R. Martins and E. Fortunato
}

Additional information is available at the end of the chapter

http://dx.doi.org/10.5772/61216

\begin{abstract}
The motivation of using metal oxides is mainly due to its charge storage capabilities, and electrocatalytic, electrochromic and photoelectrochemical properties. But comparing with bulk, nanostructured materials present several advantages related with the spatial confinement, large fraction of surface atoms, high surface energy, strong surface adsorption and increased surface to volume ratio, which greatly improves the performances of these materials. The deposition of this materials can be accomplished by a variety of physical and chemical techniques but nowadays, electrodeposited metal oxides are generally used in both laboratories and industries due to the flexibility to control structure and morphology of the oxide electrodes combined with a reduced cost. Tungsten oxide $\left(\mathrm{WO}_{3}\right)$ is a well-studied semiconductor and is used for several applications as chromogenic material, sensor and catalyst. The major important features is its low cost and availability, improved stability, easy morphologic and structural control of the nanostructures, reversible change of conductivity, high sensitivity, selectivity and biocompatibility. For the electrodeposition of $\mathrm{WO}_{3}$, more than one method can be adopted: electrodeposition from a precursor solution, anodic oxidation, and electrodeposition of already produced nanoparticles; however, in this case the mechanism of the electrodeposition is not fully understood. In this chapter, a review of the latest published work of electrodeposited nanostructured metal oxides is provided to the reader, with a more detailed explanation of $\mathrm{WO}_{3}$ material applied in sensing devices.
\end{abstract}

Keywords: tungsten oxide, $\mathrm{pH}$ sensor, neural recordings, impedance

\section{Introduction}

Over the past two decades, the revolution in materials science has driven great advances in all areas of science and engineering. Nanoscience and nanotechnology are leading this revolution 
fueled by the industrial progress, the scientific ability to fabricate, model, and manipulate objects with a small number of atoms, and the continuous discovery of new phenomena at the nanoscale [1, 2]. Nanomaterials present unique properties, which are not found in the respective bulk materials [3]. Surface and quantum effects arise in nanostructures due to the large surface-to-volume ratio and to the dimensions that are comparable to the electron wavelength, respectively $[4,5]$.

In the metal oxides field, the discovery of superconductivity [6] and large magnetoresistance [7] has raised researchers' attention, especially to those with transition metals. Moreover, in traditional electronics, oxides are widely used as semiconductors, dielectrics, and conductive electrodes [8]. In the last years, nanostructured metal oxides for sensing applications have achieved significant advances, mainly due to their better thermal and environmental stability compared with organic materials. These devices, based on nanomaterials, can operate with low power consumption and can be easily integrated with nanoelectronics. Furthermore, the construction of sensors in "low-cost" substrates, such as plastic, paper, or textile, is also in demand for application in portable consumer devices [9-13]. Electrodeposition, in this case, is of great interest due to its flexibility to control the structure and morphology of the oxide electrodes combined with the reduced cost $[14,15]$.

\section{Electrodeposition}

The term electrodeposition is often used unclearly, referring either to electroplating or to electrophoretic deposition (EPD) [16]. The electroplating process is based on a solution of ionic species, usually in water, while EPD occurs in a suspension of particles. In electroplating, there is a charge transfer during the deposition to produce the metal or oxide layer in the electrode, while in EPD the deposition occurs without any reaction involved (Fig. 1). In fact, the principal driving force for EPD is the charge and the electrophoretic mobility of the particles in the solvent under the influence of an applied electric field, with the drawback that the solvent should be organic in order to avoid water electrolysis [16, 17].
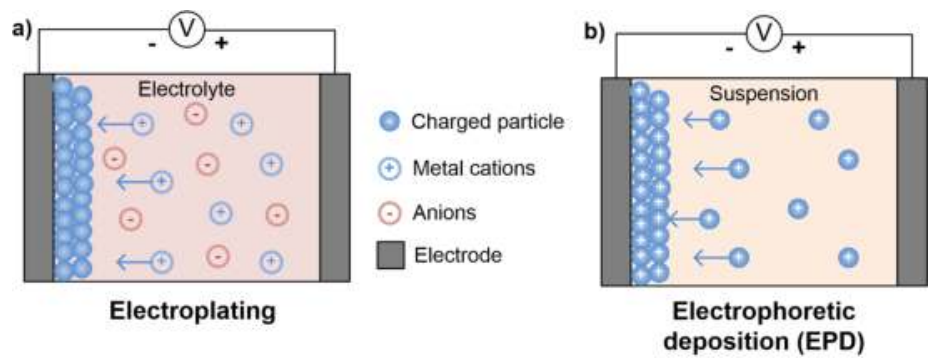

Figure 1. Schematic representation of the two types of cathodic electrodeposition processes: (a) electroplating and (b) electrophoretic deposition (EPD). 
Another variation of an electrochemical deposition is the electroless (autocatalytic) deposition in which a reducing agent, dissolved in the electrolyte, is the electron source for the redox reaction, and no external power supply is needed [18]. Nevertheless, the electroless deposition will not be discussed in this chapter.

The first reports on the electrodeposition technique date back to the 19th century; however, the understanding of the process and the electrochemistry involved was only developed in the 20th century and it is believed that further research is still needed to optimize the process [16].

In electroplating, the relation between the current and the overpotential of electrodeposition is given by the Tafel equation (Equation 1), which describes the exponential dependence between the two parameters. Worth mentioning is that with the increase of the overpotential, the ionic current that the electrolyte can supply is limited either by material transport or electrical conductivity $[15,19]$.

$$
\mathrm{i}=-\mathrm{FkC} \exp \left(\frac{\alpha \mathrm{F} \eta}{\mathrm{RT}}\right)
$$

where $i$ is the current, $F$ is Faraday's constant, $k$ a constant, $C$ the concentration of metal ions in solution (which can be initially dissolved in the electrolyte or originated from the dissolution of the metallic anode), $\alpha$ the coefficient of symmetry $(\sim 0.5), \eta$ the overpotential, $R$ the ideal gas constant, and $T$ the absolute temperature $(\mathrm{K})$.

The first attempt to correlate the amount of particles deposited by EPD with the different parameters influencing electrophoresis was first described by Hamaker for electrophoretic cells with a planar geometry. Over the years, Hamaker's law has been adapted and more recently Equation 2 was derived, relating the weight $(W)$ of the charged particles deposited per unit area of electrode in the initial period, with different parameters, and disregarding the charge of the free ions [20].

$$
\mathrm{W}=\frac{2}{3} \mathrm{C} \varepsilon_{0} \varepsilon_{\mathrm{r}} \xi \mu^{-1} \mathrm{EL}^{-1} \mathrm{t}
$$

Here, $C$ is the concentration of the particles; $\varepsilon_{0}$ and $\varepsilon_{\mathrm{r}}$ the permittivity of vacuum and solvent, respectively; $\xi$ the zeta potential of the particles; $\mu$ the viscosity of the solvent; $E$ the applied potential; $L$ the distance between the electrodes; and $t$ the deposition time. Equation 2 demonstrates that the deposition weight of the charged particles under ideal EPD depends on all the previous parameters. However, if the solvent, the particles, and the apparatus for EPD are not changed, the weight of the deposited particles $(W)$ is a function of $C, E$, and $t$. Therefore, the mass of the deposited particles, namely the thickness of the films, can be easily controlled by the concentration of the suspension, applied potential, and deposition time [17].

Electrodeposition of conventional metals for coatings has a very long history, with more than 200 years for some metals and alloys. Today, electrodeposition is much more than just a 
technique for coatings fabrication. In addition to applications such as decorative, wear, and corrosion-protective coatings, electrodeposition is also used for the manufacture of molds, functional coatings for magnetic and electronic applications, and microelectromechanical system components production [5]. In the future, though traditional applications will continue, new ones will rapidly develop, especially in the fields of nanoelectronics, biotechnology, and energy engineering. The electrodeposition of non-metallic materials will become more important and the combination of electrodeposition with other processes will lead to nanostructured materials with new and improved properties [21, 22]. Electrodeposition is extremely versatile and different applications will keep being explored [23].

\section{Metal oxide electrodeposition}

Metal oxides are an important class of materials, which benefit from the large electronegativity of oxygen to induce strong bonding with nearby atoms [22]. At the same time, when compared with bulk materials, nanostructured metal oxides benefit from the spatial confinement, the large fraction of surface atoms, high surface energy, strong surface adsorption, and increased surface-to-volume ratio that greatly improves the performance of these materials [24].

The deposition of nanostructured metal oxides has been already reported by both physical and chemical methods $[8,5]$. The advantages of electrodeposition include its speed, low cost, high purity, industrial applicability, use of different types of substrates, and production of films with different morphologies and compositions, as multilayers and alloys [21, 22].

In the electroplating of metal oxides, the reaction involved is usually defined by two consecutive steps (Equation 3). First, the hydroxide will precipitate in the surface of the electrode due to the reaction of the metal ion $\left(\mathrm{M}^{\mathrm{n}+}\right)$ in an alkaline solution, and secondly, the oxide is formed through a condensation/dehydration process. This last step can occur either during electrodeposition or by a subsequent annealing procedure [15].

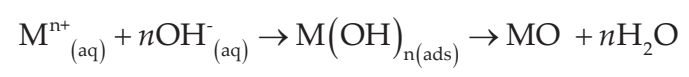

Another alternative is the formation of metal oxides by anodic oxidation [15]. In this case, the source of the metal ions is the metallic anode and the metal oxide film will be deposited on top of the metal electrode. The general equation can be described as (Equation 4):

$$
\mathrm{M}+m \mathrm{H}_{2} \mathrm{O} \leftrightarrow \mathrm{MO}_{\mathrm{m}(\mathrm{s})}+2 m \mathrm{H}_{(\mathrm{aq})}^{+}+2 m \mathrm{e}^{-}
$$

In EPD, the metal oxide nanoparticles are generally synthesized by different solution based techniques, e.g., sol-gel, precipitation, and hydrothermal synthesis, prior to deposition. The main challenge of this technique is the preparation of a stable dispersion that originates a film with good properties, uniformity, and appropriate thickness. The use of dispersants, binders, 
or other additives that influences the agglomeration and charge of the particles contributes to the tuning of the properties of the deposited film and need to be considered in defining the EPD parameters [16].

\subsection{Applications}

Nowadays, electrodeposited nanostructured metal oxides are generally used for different applications in laboratories and industry [15]. The latest published reports on the field, listed in Table 1, evidentiate the diversity of areas where these materials can be applied, as presented below.

The deposition of metal/metal oxide nanoparticles composites allowed advances on the protective coatings field. Sajjadnejad et al. [25] improved the corrosion resistance of zinc by co-depositing $\mathrm{TiO}_{2}$ nanoparticles, while Zeng et al. [26] incorporated $\mathrm{CeO}_{2}$ nanoparticles to improve the corrosion behavior of nickel coatings. Charlot et al. [27] opened the discussion of the kinetics and mechanism of the anodic EPD of $\mathrm{SiO}_{2}$ nanoparticles to improve the control of the thickness and properties of these coatings (Fig. 2).

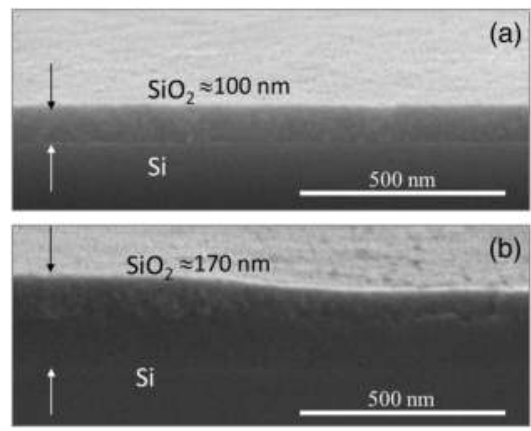

Figure 2. Scanning electron microscopy (SEM) images of a film cross-section obtained from a suspension with a mass fraction of $3 \%$ of nanoparticles under an applied electric field of (a) $6 \mathrm{~V} \mathrm{~cm}^{-1}$ and of (b) $60 \mathrm{~V} \mathrm{~cm}^{-1}$. Reprinted from [27], with permission from Elsevier.

Metal oxide nanostructures are already known to show good catalytic properties. Tu et al. [28] produced $\mathrm{Cu}_{2} \mathrm{O}-\mathrm{Cu}$ nanoparticles in carbon paper via electroplating. This procedure is an easy, one-step technique that can be an attractive candidate as a visible-light-driven photocatalyst. At the same time, Yoon et al. [29] studied the influence of 2D and 3D structures on electrodeposited $\mathrm{Cu}_{2} \mathrm{O}$ films by controlling the electrolyte $\mathrm{pH}$ and by using polystyrene (PS) beads as template, respectively. This techniques allowed the production of electrodes with increased surface area. Battaglia et al. [30] also improved the catalytic performance of different $\mathrm{Ni}$ electrodes by electrodepositing $\mathrm{IrO}_{2}$ nanostructures through different electrochemical methods. The composites obtained by galvanostatic deposition of the oxide catalyst presented the best activity for water splitting applications. 
Solid oxide fuel cells (SOFC) have shown to be a good alternative for electric power generation systems. SOFC show high energy conversion efficiency, clean power generation, reliability, modularity, fuel adaptability, noise-free, excellent long-term stability, and versatility for direct conversion of chemical energy to electrical energy. In this field, Das and Basu [31] applied the EPD technique to deposit yttria-stabilized zirconia (YSZ) nanoparticles on a NiO-YSZ substrate, which after sintering was suitable for application in SOFC (Fig. 3).
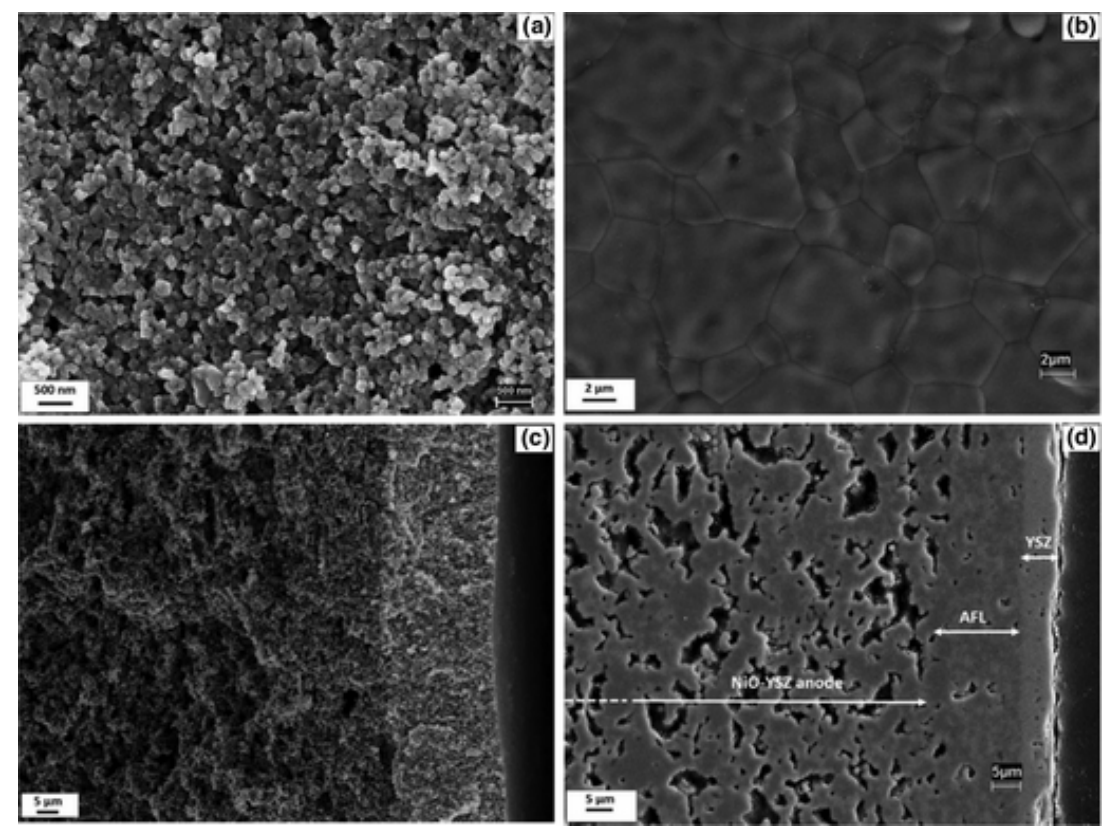

Figure 3. Field-emission SEM images of top view and cross-section of yttria-stabilized zirconia (YSZ) electrophoretic deposition coating (a) (c) as-deposited and (b) (d) sintered at $1400{ }^{\circ} \mathrm{C}$ for $6 \mathrm{~h}$, directly deposited onto the conducting polymers such as polypyrrole-coated NiO-YSZ substrate at a constant applied voltage of $15 \mathrm{~V}$. Reprinted from [31], with permission from John Wiley and Sons.

EPD was also the technique used to deposit $\mathrm{TiO}_{2}$ nanoparticles for dye-sensitized solar cells (DSSC) [32] and Li-ion micro-batteries applications [33]. For DSSC, the thickness of the $\mathrm{TiO}_{2}$ films was controlled by changing the deposition time and the $\mathrm{I}_{2}$ dosage that electrically charge the nanoparticles, while for batteries, the EPD was performed with different $\mathrm{TiO}_{2}$ structures and different 3D aluminum collectors configurations (Fig. 4). The effect of the substrate was also tested in the EPD of $\mathrm{ZnO}$ nanoparticles for conductive fabrics applications [34]. Liu et al. [35] studied the EDP of metal oxides using celestine blue as charging and dispersing agent. The nanostructured $\mathrm{MnO}_{2}$ films were applied for energy storage in electrochemical supercapacitors with high capacitance and excellent capacitance retention at high charge-discharge rates. 

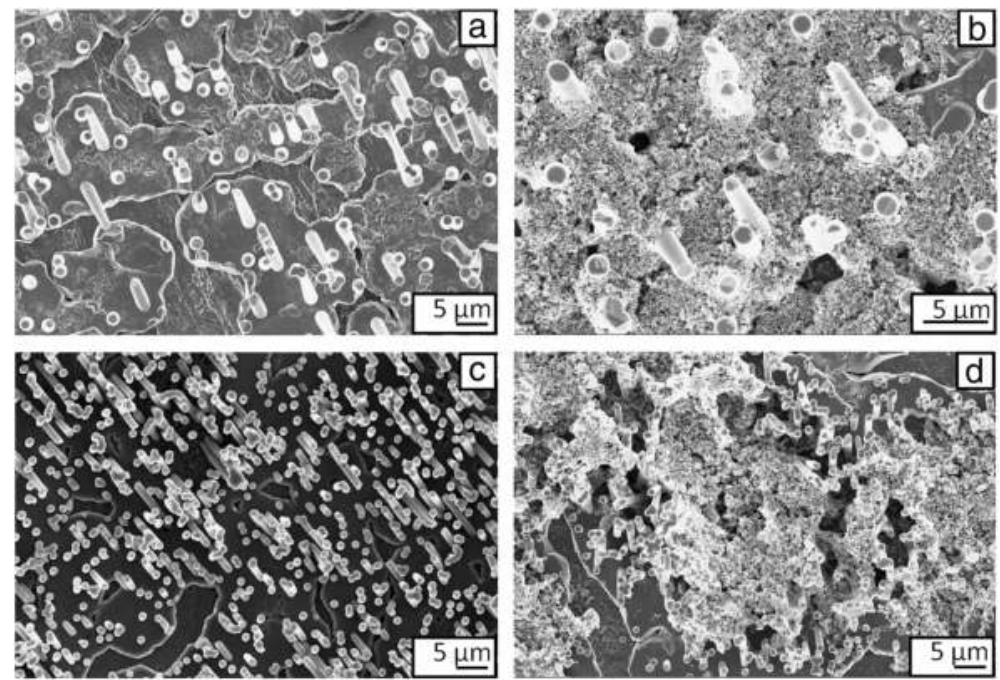

Figure 4. SEM micrographs of aluminium rods obtained by pulsed galvanostatic deposition using a PC membrane with (a) $2 \mu \mathrm{m}$-pore size and (c) $1 \mu \mathrm{m}$-pore size with electrophoretically deposited P25 particles attached to the respective 3D Al substrates (b) and (d). Reprinted from [33], with the permission from Elsevier.

The use of metal oxides offers functionalities that vary from electrically conducting to insulating and from highly catalytic to inert, which are useful for sensing applications. Different types of metal oxide sensors have been investigated for several decades, and it has been proved that the reduction of crystallite size provided a significant increase in the sensing performances. Even if less established, these type of sensors are very promising and new developments are being accomplished every day [36].

Recently, $\mathrm{Cu}_{2} \mathrm{O}$ nanostructures were electroplated to produce a facile and economic photoelectrochemical sensor [37], while $\mathrm{Ir}_{2} \mathrm{O}_{3}$ was deposited in stretchable and multiplexed $\mathrm{pH}$ sensors [38]. This sensor combined electrochemical, microfabrication, and printing techniques and was successfully applied in beating explanted cardiac tissue, with accurate spatiotemporal monitoring of changes in $\mathrm{pH}$ (Fig. 5).

Monitoring analgesic drugs with the use of biosensors allows a rapid, reliable, and sensitive method without the requirement of a sample pre-treatment. For that, alloys deposition allows the combination of different materials properties without compromising thickness or surface area available. The biosensors developed by Narang et al. [39] were produced by EPD of an $\mathrm{Fe}_{2} \mathrm{O}_{3}$ magnetic nanoparticle coated with $\mathrm{ZrO}$ suspension containing chitosan, prior to enzyme (horseradish peroxidase) immobilization. Also the combination of $\mathrm{Fe}_{2} \mathrm{O}_{3}$ with carbon nanotubes and chitosan was earlier used by Batra et al. [40] to immobilize hemoglobin and were applied as an amperometric biosensor. 


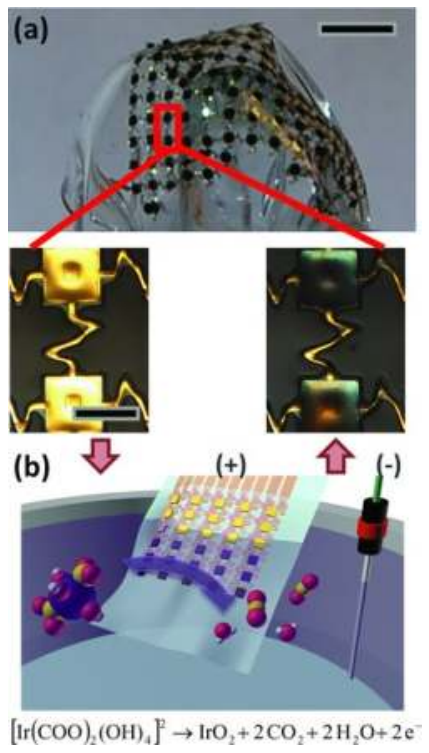

Figure 5. (a) Picture of the produced $\mathrm{pH}$ sensors with the magnified images of the gold electrodes before (lower left) and after (lower right) $\mathrm{IrO}_{x}$ electroplating. The scale bars correspond to 5 and $0.5 \mathrm{~mm}$ for the upper and the lower images, respectively. (b) Schematic illustration of the chemical reactions during $\mathrm{IrO}_{\mathrm{x}}$ electroplating. Reprinted from [38], with permission from John Wiley and Sons.

\begin{tabular}{|c|c|c|}
\hline Application & Nanomaterials/Composites & References \\
\hline Corrosion and wear resistive coatings & $\mathrm{Zn}-\mathrm{TiO}_{2}, \mathrm{Ni}-\mathrm{CeO}_{2}, \mathrm{SiO}_{2}$ & {$[25][26][27]$} \\
\hline Photocatalyst & $\mathrm{Cu}_{2} \mathrm{O}-\mathrm{Cu}, \mathrm{Cu}_{2} \mathrm{O}$ & [28][29] \\
\hline Water splitting & $\mathrm{Ni}-\mathrm{IrO}_{2}$ & [30] \\
\hline Solid oxide fuel cell & $\mathrm{Y}_{2} \mathrm{O}_{3}-\mathrm{ZrO}_{2}(\mathrm{YSZ})$ & {$[31]$} \\
\hline Dye-sensitized solar cell & $\mathrm{TiO}_{2}$ & [32] \\
\hline Li-ion micro-battery & $\mathrm{TiO}_{2}$ & [33] \\
\hline Conductive fabric & $\mathrm{ZnO}$ & {$[34]$} \\
\hline Supercapacitor & $\mathrm{MnO}_{2}$ & {$[35]$} \\
\hline Photoelectrochemical sensor & $\mathrm{Cu}_{2} \mathrm{O}$ & [37] \\
\hline $\mathrm{pH}$ sensor & $\mathrm{Ir}_{2} \mathrm{O}_{3}$ & {$[38]$} \\
\hline Biosensor & $\mathrm{ZrO} @ \mathrm{Fe}_{3} \mathrm{O}_{4}, \mathrm{cMWCNT}-\mathrm{Fe}_{3} \mathrm{O}_{4}$ & [39][40] \\
\hline
\end{tabular}

Table 1. List of the latest published research on electrodeposited metal oxide nanostructures/nanomaterials. 


\section{Nanostructured $\mathrm{WO}_{3}$}

Tungsten oxide $\left(\mathrm{WO}_{3}\right)$ is a well-studied semiconductor used for several applications such as chromogenic material, sensor, and catalyst [41]. The major advantages is its low cost and availability, improved stability, reversible change of conductivity and optical properties, high sensitivity, selectivity, and biocompatibility [42].

Transition-metal oxides, especially those with $\mathrm{d}^{0}$ and $\mathrm{d}^{10}$ electronic configurations, as $\mathrm{WO}_{3}$, $\mathrm{TiO}_{2}$, or $\mathrm{ZnO}$ show interesting properties and stability that are important for sensing applications [43]. The energy band gap of $\mathrm{WO}_{3}$ corresponds to the difference between the energy levels of the valence band formed by the filled $\mathrm{O} 2 \mathrm{p}$ orbitals and the conduction band formed by empty W $5 \mathrm{~d}$ orbitals, ranging from 2.6 to $3.25 \mathrm{eV}$ [44]. In nanostructured $\mathrm{WO}_{3}$, the bandgap generally increases with the reduction of the grain size, which is attributed to the quantum confinement effect [45]. Tungsten oxide is also well known for its properties in a non-stoichiometric form, since its lattice can support a significant concentration of oxygen vacancies [44].

\section{1. $\mathrm{WO}_{3}$ electrodeposition}

Many liquid and vapor phase synthesis methods have been used to synthesize $\mathrm{WO}_{3}$ [45]. Nevertheless, for the electrodeposition of nanostructured $\mathrm{WO}_{3}$ films, more than one method can be adopted: electroplating from a precursor solution [46, 47], anodic oxidation from a metal layer [47-49], and electrodeposition from a $\mathrm{WO}_{3}$ nanoparticles dispersion [50, 51]. A list of the latest reports is presented in Table 2 .

\begin{tabular}{|c|c|c|c|}
\hline $\mathrm{WO}_{3}$ Precursor & Nanostructured film & Application & References \\
\hline $\mathrm{Na}_{2} \mathrm{WO}_{4}$ & $\mathrm{WO}_{3}$ & -- & [59] \\
\hline $\mathrm{Na}_{2} \mathrm{WO}_{4}$ & $\mathrm{Pt}-\mathrm{WO}_{3}$ & Proton exchange membrane fuel cell & [53] \\
\hline $\mathrm{Na}_{2} \mathrm{WO}_{4}$ & $\mathrm{TiO}_{2}-\mathrm{WO}_{3}$ & Photocatalyst & {$[60]$} \\
\hline $\mathrm{Na}_{2} \mathrm{WO}_{4}$ & $\mathrm{TiO}_{2}-\mathrm{WO}_{3}$ & Water splitting & {$[61]$} \\
\hline $\mathrm{H}_{2} \mathrm{WO}_{4}$ & $\mathrm{WO}_{3} / \mathrm{PANI}$ & Supercapacitor & [52] \\
\hline PTA & $\mathrm{WO}_{3}$ & Electrochromic film & [46] \\
\hline PTA & $\mathrm{WO}_{3} / \mathrm{PEDOT}$ & Electrochromic film & {$[62]$} \\
\hline $\mathbf{W}$ & $\mathrm{WO}_{3}$ & -- & {$[57]$} \\
\hline W & $\mathrm{WO}_{3} / \mathrm{PANI}$ & Electrocatalyst & {$[48]$} \\
\hline W & $\mathrm{TiO}_{2}-\mathrm{WO}_{3}$ & Photoelectrocatalyst & {$[63]$} \\
\hline $\mathbf{W}$ & $\mathrm{WO}_{3}$ & Photoelectrocatalyst & {$[64]$} \\
\hline W & $\mathrm{WO}_{3}$ & Photocatalyst & {$[65]$} \\
\hline $\mathbf{W}$ & $\mathrm{NH}_{4}$-doped $\mathrm{WO}_{3}$ & Water splitting & {$[49]$} \\
\hline W & $\mathrm{TiO}_{2}-\mathrm{WO}_{3}$ & Water splitting & {$[66]$} \\
\hline
\end{tabular}




\begin{tabular}{llll}
\hline $\mathbf{W O}_{3}$ Precursor & Nanostructured film & Application & References \\
\hline $\mathbf{W}$ & $\mathrm{WO}_{3}-\mathrm{TiO}_{2}$ & Electrochromic film & {$[54]$} \\
\hline $\mathbf{W}$ & $\mathrm{WO}_{3}$ & $\mathrm{H}_{2}$ sensor & {$[67]$} \\
\hline $\mathbf{W O} \mathbf{N P s}_{3}$ & $\mathrm{WO}_{3} /$ henna & Dye sensitized solar cells & {$[68]$} \\
\hline $\mathbf{W O} \mathbf{N P s}$ & $\mathrm{WO}_{3}$ & Water splitting & {$[51]$} \\
\hline $\mathbf{W O}_{3} \mathrm{NWs}$ & $\mathrm{WO}_{3}$ & Electrochromic film & {$[58]$} \\
\hline $\mathbf{W O}_{3} \mathbf{N P s}$ & $\mathrm{WO}_{3}$ & Electrochromic film & {$[50]$} \\
\hline $\mathbf{W O}_{3} \mathbf{N P s}$ & $\mathrm{WO}_{3}$ & pH sensor & {$[12]$} \\
\hline $\mathbf{W O}_{3} \mathbf{N P s}$ & $\mathrm{WO}_{3}$ & Neural electrodes & {$[69]$} \\
\hline
\end{tabular}

Table 2. Resume of the latest published research on electrodeposited nanostructured $\mathrm{WO}_{3}$ with the respective precursors and final applications.

Cathodic electroplating is usually based on the local increase of the $\mathrm{pH}$ near the electrode surface due to the reduction of $\mathrm{O}_{2}$ or $\mathrm{H}_{2} \mathrm{O}$, which induces precipitation of metal ions present in the solution as metal oxide or hydroxide. For the deposition of $\mathrm{WO}_{3}$, the reactions involved in the formation of the oxide are usually based on the formation of the peroxytungstate $\left(\mathrm{W}_{2} \mathrm{O}_{11}{ }^{2-}\right)$ intermediate from a tungstate salt (or from the reaction of metallic tungsten with hydrogen peroxide), as described in Equations 5 and 6 [46, 52].

$$
\begin{gathered}
2 \mathrm{WO}_{4}{ }^{2-}+4 \mathrm{H}_{2} \mathrm{O}_{2}+2 \mathrm{H}^{+} \rightarrow \mathrm{W}_{2} \mathrm{O}_{11}{ }^{2-}+5 \mathrm{H}_{2} \mathrm{O} \\
\mathrm{W}_{2} \mathrm{O}_{11}{ }^{2-}+2 \mathrm{H}^{+} \rightarrow 2 \mathrm{WO}_{3}+2 \mathrm{O}_{2}+\mathrm{H}_{2} \mathrm{O}
\end{gathered}
$$

Depending on the electrochemical potential and solution $\mathrm{pH}$, the $\mathrm{WO}_{3}$ phase may also be involved in other reactions, as the formation of sub-stoichiometric oxide and tungsten bronze (Equations 7 and 8) or even re-dissolution of the oxide phase (Equation 9). The reduced phases formed by these reactions have higher conductivity and hydrophilicity than $\mathrm{WO}_{3}$ and should be considered during characterization of the deposited films [53].

$$
\begin{gathered}
\mathrm{WO}_{3}+2 y \mathrm{H}^{+}+2 y \mathrm{e}^{-} \leftrightarrow \mathrm{WO}_{3-y}+y \mathrm{H}_{2} \mathrm{O} \\
\mathrm{WO}_{3}+x \mathrm{H}^{+}+x \mathrm{e}^{-} \leftrightarrow \mathrm{H}_{x} \mathrm{WO}_{3} \\
\mathrm{WO}_{3}+\mathrm{H}_{2} \mathrm{O} \rightarrow \mathrm{WO}_{4}{ }^{2-}+2 \mathrm{H}^{+}
\end{gathered}
$$


For the anodic oxidation procedure, the general equation can be expressed as Equation 10 [54] and the full mechanism is explained by the occurrence of different reactions simultaneously, as the synthesis of surface oxide films (e.g., $\mathrm{W}_{2} \mathrm{O}_{5}, \mathrm{WO}_{2}$ ) and tungstate ions $\left(\mathrm{WO}_{4}^{2-}\right)[55,56]$. This oxidation is usually followed by the slow dissolution of the oxide phase, as in Equations 11 or 12 depending on the solution $\mathrm{pH}[55,57]$.

$$
\begin{gathered}
\mathrm{W}+3 \mathrm{H}_{2} \mathrm{O} \leftrightarrow \mathrm{WO}_{3}+6 \mathrm{H}^{+}+6 \mathrm{e}^{-} \\
\mathrm{WO}_{3}+2 \mathrm{H}^{+} \rightarrow \mathrm{WO}_{2}{ }^{2+}+\mathrm{H}_{2} \mathrm{O} \\
\mathrm{WO}_{3}+2 \mathrm{OH}^{-} \rightarrow \mathrm{WO}_{4}{ }^{2-}+\mathrm{H}_{2} \mathrm{O}
\end{gathered}
$$

In the case of the deposition from $\mathrm{WO}_{3}$ nanoparticles dispersions (EPD), the mechanism is not yet fully understood. The majority of the authors agree that the deposition occurs through an electrophoretic mechanism driven by the surface charge of the particles [51, 58], but in fact, the potential (or current) applied during deposition can also promote tungsten reduction from $\mathrm{W}^{6+}$ to $\mathrm{W}^{5+}$ that is counterbalanced by the cation intercalation into the oxide structure, as described in Equation 8, thus forming tungsten bronze $\left(\mathrm{H}_{x} \mathrm{WO}_{3}\right)$ [50]. In the work of Liu et al. [50], XRD and optical characterization showed that $\mathrm{HWO}_{3}$ was obtained as the main phase of the deposited films, which supports the hypothesis of the mechanism via electrochemical reduction. Furthermore, since the reduced $\mathrm{WO}_{3}$ is significantly more conductive than the oxidized form, it allowed continuous film growth. In the future, further analysis of the deposited films should be conducted to confirm the electrochemical deposition mechanism.

\section{2. $\mathrm{WO}_{3}$ sensing applications}

\subsubsection{Gas sensors}

Precise and affordable monitoring of chemical gases is a critical issue for human health, industrial processes, and environmental protection. For that, nanostructured $\mathrm{WO}_{3}$ has been intensively studied due to its excellent sensing capabilities and reproducibility. These characteristics are mainly ascribed to the increased surface area and complete depletion of carriers within the nanostructure when exposed to the target gas [45]. The gas sensing mechanism is described by the increase or decrease of the conductance of the oxide layer when exposed to reducing $\left(\mathrm{H}_{2}, \mathrm{H}_{2} \mathrm{~S}, \mathrm{CO}\right)$ or oxidizing $\left(\mathrm{NO}_{2}, \mathrm{O}_{3}, \mathrm{CO}_{2}\right)$ gases, respectively.

$$
\mathrm{H}_{2}+\mathrm{O}_{\text {ads }}^{-} \rightarrow \mathrm{H}_{2} \mathrm{O}+\mathrm{e}^{-}
$$

In Equation 13, $\mathrm{H}_{2}$ adsorbs and reacts with $\mathrm{O}^{-}$formed on the surface of the electrode, increasing the surface conductance and releasing the captured electrons [67]. 


$$
\begin{gathered}
\mathrm{NO}_{2}+\mathrm{e}^{-} \rightarrow \mathrm{NO}_{2}^{-} \\
2 \mathrm{NO}_{2}+2 \mathrm{O}_{\text {ads }}^{-} \rightarrow 2 \mathrm{NO}_{2}^{-}+\mathrm{O}_{2}
\end{gathered}
$$

When $\mathrm{NO}_{2}$ is targeted on the $\mathrm{WO}_{3}$ surface, it not only reacts with the electrons from the conduction band (Equation 14) but also with the chemisorbed oxygen (Equation 15), thus promoting a depletion on the surface of the electrode and, consequently, the increase on resistance $[70,71]$.

An example of a hydrogen gas sensor was built by Yang et al. [67] through anodic oxidation of a tungsten layer previously deposited by radio frequency magnetron sputtering on a sapphire substrate (Fig. 6). The nanoporous $\mathrm{WO}_{3}$ film sensor, after annealing at $600^{\circ} \mathrm{C}$, exhibited good sensitivity to $\mathrm{H}_{2}$ gas in air.
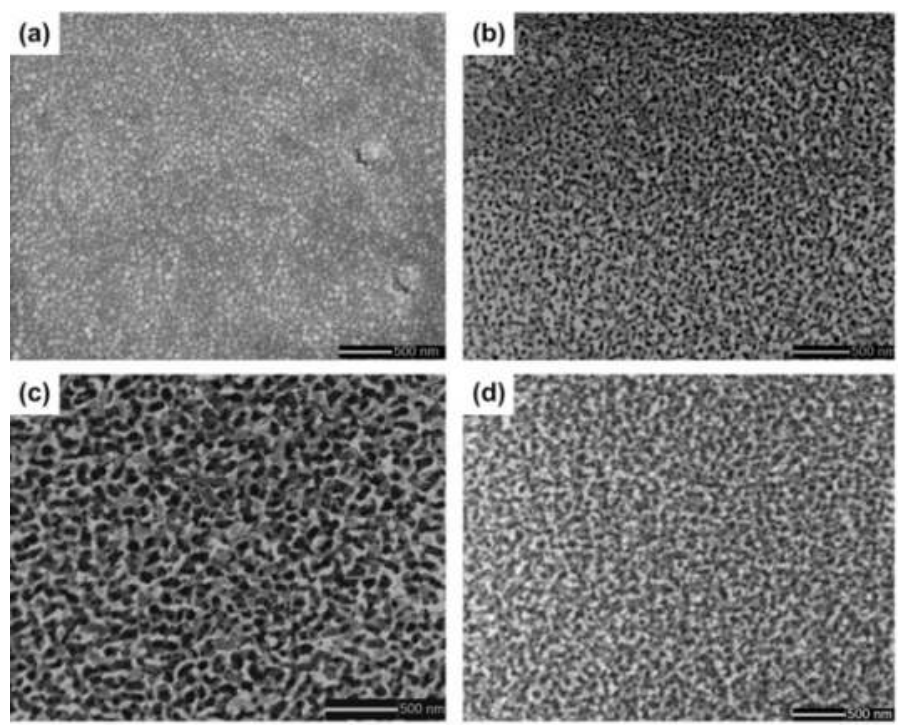

Figure 6. SEM images of tungsten oxide films with different anodic oxidation voltages: (a) $20 \mathrm{~V}$, (b) $30 \mathrm{~V}$, (c) $50 \mathrm{~V}$, and (d) $60 \mathrm{~V}$ operating at an electrode distance of $2 \mathrm{~cm}$ for $60 \mathrm{~min}$. Reprint from [67], with permission from Cambridge University Press.

\subsubsection{Biosensors}

The application of $\mathrm{WO}_{3}$ to other sensing platforms, as in biosensors, is mainly due to the electrical and optical properties mentioned above [72]. In fact, it was already demonstrated that nanoparticles of metal oxides applied to suitable electrode surfaces allow protein immobilization and biocatalytic processes to be driven electrochemically [73]. However, to the best of the authors' knowledge, only Feng et al. [74] employed electrodeposited nanostructured 
$\mathrm{WO}_{3}$ films to enhance the hemoglobin protein loadings, accelerate interfacial electron transfer, and improve thermal stability of the adsorbed protein. The influence of the electrodeposition time to the response time and peak current of the electrode is demonstrated in Fig. 7.

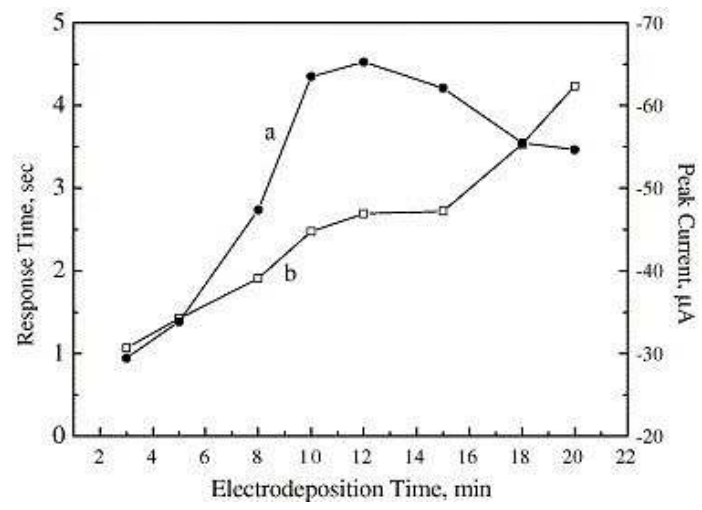

Figure 7. Influence of electrodeposition time on (a) peak current of the cyclic voltammograms in phosphate buffer solution (PBS, pH 6.0) at $100 \mathrm{mV} \mathrm{s}^{-1}$ and (b) typical steady-state response time of $\mathrm{Hb} / \mathrm{meso}-\mathrm{WO}_{3} /$ graphite electrodes. Reprinted from [74], with permission from Elsevier.

\subsection{3. $\mathrm{pH}$ sensors}

The $\mathrm{pH}$ value can be used as an indicator for disease diagnostics, medical treatment optimization, and monitoring of biochemical and biological processes [75]. Nevertheless, the integration of $\mathrm{pH}$ sensing systems into the next generation of wearable devices requires a different architecture than currently used in typical glass-type electrodes and a minimal electrode size [76]. In addition, technological and industrial efforts are under way to incorporate different sensors into our daily life by assembling these sensors on common substrates such as plastic, textile, and paper [9]. In the work reported earlier [12], flexible $\mathrm{pH}$ sensors were based on electrodeposited $\mathrm{WO}_{3}$ sensing layer in a gold/polyimide substrate (Fig. 8). The $\mathrm{pH}$ sensing mechanism for this material, even if not fully understood, is believed to be dependent of the redox reaction involving the production of the tungsten bronze with a higher conductivity than the tungsten oxide (Equation 8).

\subsubsection{Neural electrodes}

Microtechnology allowed the arrangement of multiple microelectrodes on the same substrate over small distances (Fig. 9a). Nevertheless, in order to provide sufficient recording sensitivity to small electrodes for measuring neuron electrical activity, they are often coated with different nanostructured or conducting materials to increase the effective surface area and electrochemical interface capacitance [77-79]. The interest in utilizing transition metal oxide films is due to its pseudocapacitive character related to chemisorption processes and redox reactions that take place at the surface [80]. Since nanostructured $\mathrm{WO}_{3}$ has already proved to enhance capacitive performances due to its large surface area and low charge transport resistance [52], 

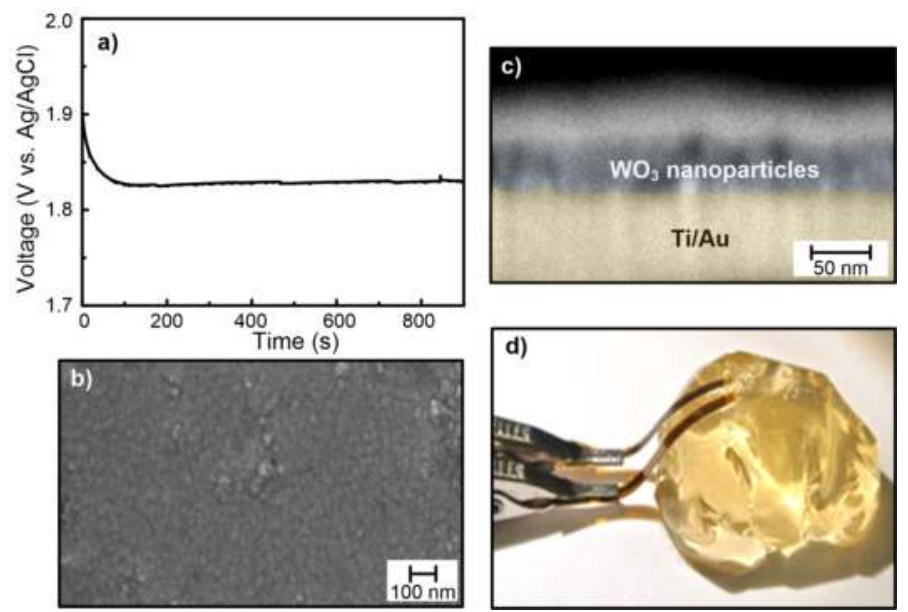

Figure 8. (a) Voltage response during electrodeposition at $20 \mu \mathrm{A}$; (b) topographic and (c) cross-section SEM images of the $\mathrm{WO}_{3}$ electrodeposited layer; and (d) photograph of the prototype $\mathrm{WO}_{3}$ sensor using a flexible $\mathrm{Ag} / \mathrm{AgCl}$ reference electrode in a non-planar surface made of gelatin-based electrolyte [12].

it was used for neural recordings applications [69]. The optimization of the electrodeposition parameters led to a slight increase on the charge storage capacity $(\sim 10 \%)$ and a decrease of the impedance values, of approximately $40 \%$ (Fig. 9b and 9c).
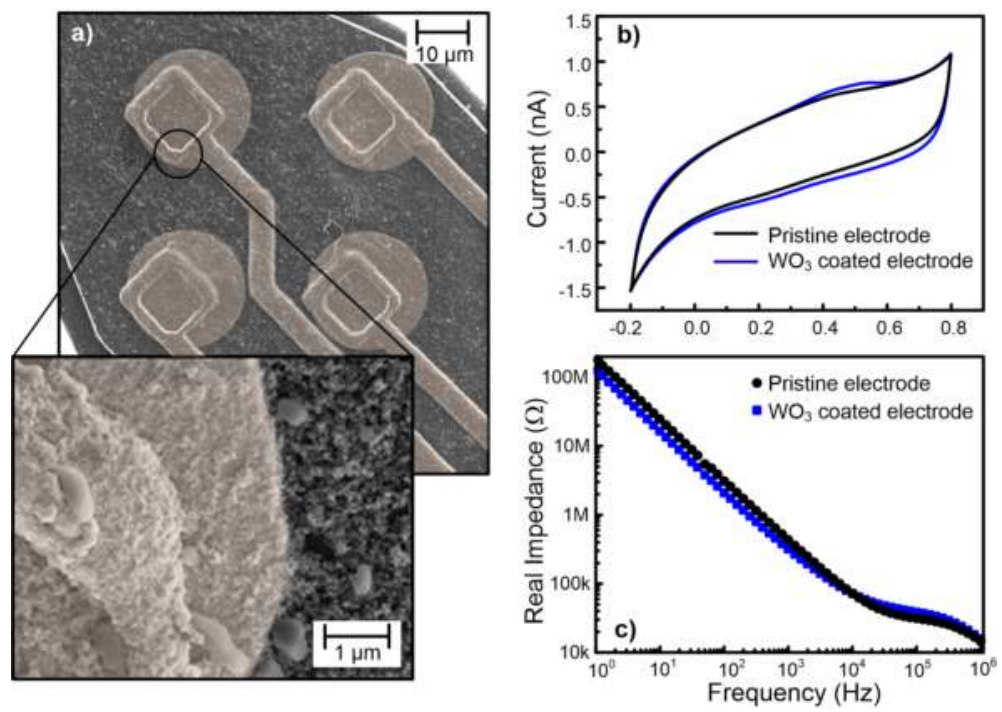

Figure 9. (a) SEM images of the Neuronexus electrode and a detail of the iridium electrode (lighter area) coated with $\mathrm{WO}_{3}$ nanoparticles, electrodeposited at $30 \mathrm{nA}$ for $15 \mathrm{~s}$; (b) cyclic voltammetry and (c) electrochemical impedance characterizations of the pristine (black) and coated electrodes (blue) [69]. 
These preliminary results show the versatility of electrodeposition in different materials and configurations as well as in different sensing mechanisms.

\section{Conclusions}

Tungsten oxide $\left(\mathrm{WO}_{3}\right)$ is one of the most studied metal oxide and the sensing performance of this material is of great interest due to the capability of reversible change of both its optical and electrical properties. The evolution in the fields of nanoscience and nanotechnology allowed these materials to replace many organic and metallic materials in a huge range of applications besides creating new areas of development. The increased surface area and the quantum confinement effects in size ranges below $100 \mathrm{~nm}$ make nanostructured $\mathrm{WO}_{3}$ a good platform for gas and $\mathrm{pH}$ sensors, along with neural electrodes and biosensors.

In the last decade, the use of electrodeposition for nanostructured metal oxide films has been growing due to the versatility of this method in different applications and materials. Just in the last year, applications varied from catalysts and sensors to capacitors. The use of different types of templates and the deposition of composites will contribute to the continued development of this technique.

\section{Acknowledgements}

The authors would like to thank the Portuguese Science Foundation (FCT-MEC) through project EXCL/CTM-NAN/0201/2012, Strategic Project UID/CTM/500025/2013, and doctoral grants SFRH/BD/73810/2010 given to L. Santos and SFRH/BD/76004/2011 given to J. Neto. The authors would like to thank Dr. Adam Kampff from Champalimaud Center of Unknown for the knowledge transfer related with neural electrodes.

\section{Author details}

L. Santos ${ }^{1 *}$, J. P. Neto ${ }^{1,2}$, A. Crespo ${ }^{1}$, P. Baião ${ }^{1,2}$, P. Barquinha $^{1}$, L. Pereira ${ }^{1}$, R. Martins ${ }^{1}$ and E. Fortunato ${ }^{1}$

*Address all correspondence to: 1s.santos@campus.fct.unl.pt; emf@fct.unl.pt

1 CENIMAT/I3N, Departamento de Ciências dos Materiais, Faculdade de Ciências e Tecnologia, Universidade Nova de Lisboa and CEMOP/Uninova, Caparica, Portugal

2 Champalimaud Centre for the Unknown, Champalimaud Neuroscience Programme, Lisbon, Portugal 


\section{References}

[1] Koch CC, Ovid'ko IA, Seal S, Veprek S. Structural Nanocrystalline Materials: Fundamentals and Applications. Cambridge, UK: Cambridge University Press; 2007.

[2] Roco MC. Broader societal issues of nanotechnology. J Nanoparticle Res 2003;5:1819.

[3] Schmid G, editor. Nanoparticles: From theory to application. Weinheim, Germany: WILEY-VCH Verlag GmbH \& Co. KGaA; 2004.

[4] Society R. Nanoscience and Nanotechnologies: Opportunities and Uncertainties. London, UK: The Royal Society \& The Royal Academy of Engineering; 2004.

[5] Koch CC, editor. Nanostructured Materials: Processing, Properties, and Applications. Norwich, NY, USA: William Andrew Publishing; 2007.

[6] Cava RJ. Oxide Superconductores. J Am Ceram Soc 2000;83:5-28.

[7] Sun JZ, Gupta A. Spin-Dependent Transport and Low-Field Magnetoresistance in Doped Manganites. Annu Rev Mater Sci 1998;28:45-78. doi:10.1146/annurev.matsci. 28.1.45.

[8] Barquinha P, Martins R, Pereira L, Fortunato E. Transparent Oxide Electronics. Chichester, UK: John Wiley \& Sons, Ltd; 2012. doi:10.1002/9781119966999.

[9] $\mathrm{Hu} \mathrm{B}$, Chen $\mathrm{W}$, Zhou J. High performance flexible sensor based on inorganic nanomaterials. Sensors Actuators B Chem 2013;176:522-33. doi:10.1016/j.snb.2012.09.036.

[10] Costa MN, Veigas B, Jacob JM, Santos DS, Gomes J, Baptista P V, et al. A low cost, safe, disposable, rapid and self-sustainable paper-based platform for diagnostic testing: Lab-on-paper. Nanotechnology 2014;25:094006. doi: 10.1088/0957-4484/25/9/094006.

[11] Branquinho R, Pinto J V, Busani T, Barquinha P, Pereira L, Baptista PV, et al. Plastic Compatible Sputtered Ta2O5 Sensitive Layer for Oxide Semiconductor TFT Sensors. J Disp Technol 2013;9:723-8.

[12] Santos L, Neto JP, Crespo A, Nunes D, Costa N, Fonseca IM, et al. WO3 Nanoparticle-Based Conformable pH Sensor. ACS Appl Mater Interfaces 2014;6:12226-34. doi: 10.1021/am501724h.

[13] Pinto JV, Branquinho R, Barquinha P, Alves E, Martins R, Fortunato E. ExtendedGate ISFETs Based on Sputtered Amorphous Oxides. J Disp Technol 2013;9:729-34. doi:10.1109/JDT.2012.2227298.

[14] Rao CNR, Muller A, Cheetham AK, editors. The chemistry of nanomaterials: Synthesis, Properties and Applications. Vol. 1. Weinheim, Germany: WILEY-VCH Verlag GmbH \& Co. KGaA; 2004. 
[15] Garcia EM, Lins VFC, Matencio T. Metallic and Oxide Electrodeposition. In: Aliofkhazraei M, editor. Mod. Surf. Eng. Treat., InTech; 2013.

[16] Besra L, Liu M. A review on fundamentals and applications of electrophoretic deposition (EPD). Prog Mater Sci 2007;52:1-61. doi:10.1016/j.pmatsci.2006.07.001.

[17] Dickerson JH, Boccaccini AR, editors. Electrophoretic Deposition of Nanomaterials. Springer; 2012.

[18] Paunovic M, Schlesinger M. Fundamentals of Electrochemical Deposition. 2nd editio. Hoboken, NJ, USA: John Wiley \& Sons, Inc.; 2006.

[19] Schlesinger M, Paunovic M, editors. Modern Electroplating. Hoboken, NJ, USA: John Wiley \& Sons, Inc.; 2010.

[20] Chen F, Liu M.Preparation of yttria-stabilized zirconia (YSZ) films on La0.85Sr0.15MnO3 (LSM) and LSM-YSZ substrates using an electrophoretic deposition (EPD) process. J Electrochem Soc 2001;21:127-34.

[21] Gurrappa I, Binder L. Electrodeposition of nanostructured coatings and their characterization-a review. Sci Technol Adv Mater 2008;9:043001. doi: 10.1088/1468-6996/9/4/043001.

[22] DjokiS, editor. Electrodeposition and Surface Finishing. New York, USA:Springer; 2014.

[23] Schwarzacher W. Electrodeposition: A Technology for the Future. Electrochem Soc Interface 2006;15:32-5.

[24] Edelstien AS, Cammarata RC, editors. Nanomaterials-Synthesis, Properties and Applications. London, UK: IOP Publishing Ltd; 1996.

[25] Sajjadnejad M, Ghorbani M, Afshar A. Microstructure-corrosion resistance relationship of direct and pulse current electrodeposited $\mathrm{Zn}-\mathrm{TiO} 2$ nanocomposite coatings. Ceram Int 2015;41:217-24. doi:10.1016/j.ceramint.2014.08.061.

[26] Zeng YB, Qu NS, Hu XY. Preparation and Characterization of Electrodeposited Ni$\mathrm{CeO} 2$ Nanocomposite Coatings with High Current Density. Int J Electrochem Sci 2014;9:8145-54.

[27] Charlot A, Deschanels X, Toquer G. Submicron coating of SiO2 nanoparticles from electrophoretic deposition. Thin Solid Films 2014;553:148-52. doi:10.1016/j.tsf. 2013.11.064.

[28] Tu J, Yuan Y, Jiao H, Jiao S. Controllable Cu2O-Cu nanoparticle electrodeposition onto carbon paper and its superior photoelectrochemical performance. RSC Adv 2014;4:16380. doi:10.1039/C4RA00592A.

[29] Yoon S, Kim M, Kim I-S, Lim J-H, Yoo B. Manipulation of cuprous oxide surfaces for improving their photocatalytic activity. J Mater Chem A 2014;2:11621. doi:10.1039/ C4TA00616J. 
[30] Battaglia M, Inguanta R, Piazza S, Sunseri C. Fabrication and characterization of nanostructured $\mathrm{Ni}-\mathrm{IrO} 2$ electrodes for water electrolysis. Int J Hydrogen Energy 2014;39:16797-805. doi:10.1016/j.ijhydene.2014.08.065.

[31] Das D, Basu RN. Electrophoretic Deposition of Zirconia Thin Film on Nonconducting Substrate for Solid Oxide Fuel Cell Application. J Am Ceram Soc 2014;97:3452-7. doi: 10.1111/jace.13163.

[32] Chou J-C, Lin S-C, Liao Y-H, Hu J-E, Chuang S-W, Huang C-H. The Influence of Electrophoretic Deposition for Fabricating Dye-Sensitized Solar Cell. J Nanomater 2014;2014:1-7. doi:10.1155/2014/126053.

[33] Oltean G, Valvo M, Nyholm L, Edström K. On the electrophoretic and sol-gel deposition of active materials on aluminium rod current collectors for three-dimensional Li-ion micro-batteries. Thin Solid Films 2014;562:63-9. doi:10.1016/j.tsf.2014.03.069.

[34] Chung Y, Park H, Baek S, Soo Y, Kim D. Processing Research Electrophoretic deposition behavior of $\mathrm{ZnO}$ nanoparticles and their properties on conductive fabrics. J Ceram Process Res 2014;15:331-5.

[35] Liu Y, Ata MS, Shi K, Zhu G-Z, Botton GA, Zhitomirsky I. Surface modification and cathodic electrophoretic deposition of ceramic materials and composites using celestine blue dye. RSC Adv 2014;4:29652. doi:10.1039/C4RA03938F.

[36] Rassaei L, Marken F, Sillanpää M, Amiri M, Cirtiu CM, Sillanpää M. Nanoparticles in electrochemical sensors for environmental monitoring. Anal Chem 2011;30:1704-15. doi:10.1016/j.trac.2011.05.009.

[37] Qiu Y, Li J, Li H, Zhao Q, Wang H, Fang H, et al. A facile and ultrasensitive photoelectrochemical sensor for copper ions using in-situ electrodeposition of cuprous oxide. Sensors Actuators B Chem 2015;208:485-90. doi:10.1016/j.snb.2014.11.061.

[38] Chung H-J, Sulkin MS, Kim J-S, Goudeseune C, Chao H-Y, Song JW, et al. Stretchable, multiplexed $\mathrm{pH}$ sensors with demonstrations on rabbit and human hearts undergoing ischemia. Adv Healthc Mater 2014;3:59-68. doi:10.1002/adhm.201300124.

[39] Narang J, Malhotra N, Singh S, Singh G, Pundir CS. Monitoring analgesic drug using sensing method based on nanocomposite. RSC Adv 2015;5:2396-404. doi:10.1039/ C4RA11255E.

[40] Batra B, Lata S, Pundir CS. Construction of an improved amperometric acrylamide biosensor based on hemoglobin immobilized onto carboxylated multi-walled carbon nanotubes/iron oxide nanoparticles/chitosan composite film. Bioprocess Biosyst Eng 2013;36:1591-9. doi:10.1007/s00449-013-0931-5.

[41] Vernardou D, Drosos H, Spanakis E, Koudoumas E, Savvakis C, Katsarakis N. Electrochemical and photocatalytic properties of WO3 coatings grown at low temperatures. J Mater Chem 2011;21:513. doi:10.1039/c0jm02413a. 
[42] Yuan S-J, He H, Sheng G-P, Chen J-J, Tong Z-H, Cheng Y-Y, et al. A photometric highthroughput method for identification of electrochemically active bacteria using a WO3 nanocluster probe. Sci Rep 2013;3:1315. doi:10.1038/srep01315.

[43] Wang C, Yin L, Zhang L, Xiang D, Gao R. Metal oxide gas sensors: Sensitivity and influencing factors. Sensors 2010;10:2088-106. doi:10.3390/s100302088.

[44] Walia S, Balendhran S, Nili H, Zhuiykov S, Rosengarten G, Wang QH, et al. Transition metal oxides - Thermoelectric properties. Prog Mater Sci 2013;58:1443-89. doi:10.1016/ j.pmatsci.2013.06.003.

[45] Zheng H, Ou JZ, Strano MS, Kaner RB, Mitchell A, Kalantar-Zadeh K. Nanostructured Tungsten Oxide - Properties, Synthesis, and Applications. Adv Funct Mater 2011;21:2175-96. doi:10.1002/adfm.201002477.

[46] More AJ, Patil RS, Dalavi DS, Mali SS, Hong CK, Gang MG, et al. Electrodeposition of nano-granular tungsten oxide thin films for smart window application. Mater Lett 2014;134:298-301. doi:10.1016/j.matlet.2014.07.059.

[47] Zhu T, Chong MN, Seng E. Nanostructured Tungsten Trioxide Thin Films Synthesized for Photoelectrocatalytic Water Oxidation: A review. ChemSusChem 2014;7:2974-97. doi:10.1002/cssc.201402089.

[48] Chen Z, Lv H, Zhu X, Li D, Zhang S, Chen X, et al. Electropolymerization of Aniline onto Anodic WO3 Film: An Approach to Extend Polyaniline Electroactivity Beyond pH 7. J Phys Chem C 2014;118:27449-58. doi:10.1021/jp509268t.

[49] Choi Y, Kim S, Seong M, Yoo H, Choi J. Applied Surface Science NH4-doped anodic WO3 prepared through anodization and subsequent $\mathrm{NH} 4 \mathrm{OH}$ treatment for water splitting. Appl Surf Sci 2015;324:414-8. doi:10.1016/j.apsusc.2014.10.059.

[50] Liu L, Layani M, Yellinek S, Kamyshny A, Ling H, Lee PS, et al. “Nano to nano” electrodeposition of WO3 crystalline nanoparticles for electrochromic coatings. J Mater Chem A 2014;2:16224-9. doi:10.1039/C4TA03431G.

[51] Rodríguez-Pérez M, Chacón C, Palacios-González E, Rodríguez-Gattorno G, Oskam G. Photoelectrochemical water oxidation at electrophoretically deposited WO3 films as a function of crystal structure and morphology. Electrochim Acta 2014;140:320-31. doi: 10.1016/j.electacta.2014.03.022.

[52] Zou B, Gong S, Wang Y, Liu X. Tungsten Oxide and Polyaniline Composite Fabricated by Surfactant-Templated Electrodeposition and Its Use in Supercapacitors. J Nanomater 2014;2014:1-9. doi:10.1155/2014/813120.

[53] Martín AJ, Chaparro AM. Influence of Operation Parameters on the Response of a PEMFC with Electrodeposited Pt-WO3 Cathode. Fuel Cells 2014;14:742-9. doi:10.1002/ fuce.201300242.

[54] Gui Y, Blackwood DJ. Electrochromic Enhancement of WO3-TiO2 Composite Films Produced by Electrochemical Anodization. J Electrochem Soc 2014;161:191-201. doi: 10.1149/2.0631414jes. 
[55] Anik M. Effect of concentration gradient on the anodic behavior of tungsten. Corros Sci 2006;48:4158-73. doi:10.1016/j.corsci.2006.03.014.

[56] Anik M, Osseo-Asare K. Effect of $\mathrm{pH}$ on the Anodic Behavior of Tungsten. J Electrochem Soc 2002;149:B224. doi:10.1149/1.1471544.

[57] Chai Y, Chin IK, Yam FK, Hassan Z. Formation of Tungsten Oxide Nanostructures Prepared in Hydrochloric Acid. J Electrochem Soc 2014;161:202-6. doi: 10.1149/2.014405jes.

[58] Moshofsky B, Mokari T. Electrochromic active layers from ultrathin nanowires of tungsten oxide. J Mater Chem C 2014;2:3556. doi:10.1039/c4tc00093e.

[59] Qi C-X, Tan Z, Feng Z-H, Yu L-P. Fabrication of bowl-like porous WO3 film by colloidal crystal template-assisted electrodeposition method. J Mater Sci Mater Electron 2014;25:1553-8. doi:10.1007/s10854-014-1767-8.

[60] Shi Y, Liu Y, Xin Y. Study on the Properties of Photocatalytic Degradation of DMP on WO3/TNas Photoelectrodes. Adv Mater Res 2014;850-851:12-5. doi:10.4028/ www.scientific.net/AMR.850-851.12.

[61] Ali H, Ismail N, Hegazy A, Mekewi M. A novel photoelectrode from TiO2-WO3 nanoarrays grown on FTO for solar water splitting. Electrochim Acta 2014;150:314-9. doi:10.1016/j.electacta.2014.10.142.

[62] Dulgerbaki C, Uygun A. Efficient Electrochromic Materials Based on PEDOT/WO3 Composites Synthesized in Ionic Liquid Media. Electroanalysis 2014;26:2501-12. doi: 10.1002/elan.201400369.

[63] Xin Y, Gao M, Wang Y, Ma D. Photoelectrocatalytic degradation of 4-nonylphenol in water with WO3/TiO2 nanotube array photoelectrodes. Chem Eng J 2014;242:162-9. doi:10.1016/j.cej.2013.12.068.

[64] Qi H, Wolfe J, Wang D, Fan HJ, Fichou D, Chen Z. Triple-layered nanostructured WO3 photoanodes with enhanced photocurrent generation and superior stability for photoelectrochemical solar energy conversion. Nanoscale 2014;6:13457-62. doi: 10.1039/c4nr03982c.

[65] Lai CW. Photocatalysis and photoelectrochemical properties of tungsten trioxide nanostructured films. Sci World J 2014;2014:843587. doi:10.1155/2014/843587.

[66] Chappanda KN, Smith YR, Rieth LW, Tathireddy P, Misra M, Mohanty SK. TiO2WO3 Composite Nanotubes from Co-Sputtered Thin Films on Si Substrate for Enhanced Photoelectrochemical Water Splitting. J Electrochem Soc 2014;161:H431-7. doi:10.1149/2.110406jes.

[67] Yang T, Zhang Y, Cai Y, Tian H. Effect of processing parameters on anodic nanoporous tungsten oxide film structure and porosity for hydrogen detection. J Mater Res 2014;29:166-74. doi:10.1557/jmr.2013.369. 
[68] Ayouchi R, Bhattacharyya SR, Barrado JRR, Schwarz R. Tungsten trioxide nanostructured electrodes for organic dye sensitised solar cells. Int J Nanotechnol 2014;11:86981.

[69] Baião P. Nanostructuring silicon probes via electrodeposition: Characterization of electrode coatings for acute in vivo neural recordings. MSc thesis. Universidade Nova de Lisboa, Portugal, 2014.

[70] Heidari EK, Zamani C, Marzbanrad E, Raissi B, Nazarpour S. WO3-based NO2 sensors fabricated through low frequency AC electrophoretic deposition. Sensors Actuators B Chem 2010;146:165-70. doi:10.1016/j.snb.2010.01.073.

[71] Bai S, Zhang K, Wang L, Sun J, Luo R, Li D, et al. Synthesis mechanism and gas-sensing application of nanosheet-assembled tungsten oxide microspheres. J Mater Chem A 2014;2:7927. doi:10.1039/c4ta00053f.

[72] Santos L, Silveira CM, Elangovan E, Neto JP, Nunes D, Pereira L, et al. Synthesis of WO3 Nanoparticles for biosensing applications. Submitted 2015.

[73] Wu Y, Hu S. Biosensors based on direct electron transfer in redox proteins. Microchim Acta 2007;159:1-17. doi:10.1007/s00604-007-0749-4.

[74] Feng J-J, Xu J-J, Chen H-Y. Direct electron transfer and electrocatalysis of hemoglobin adsorbed onto electrodeposited mesoporous tungsten oxide. Electrochem Commun 2006;8:77-82. doi:10.1016/j.elecom.2005.10.029.

[75] Zhou DD. Microelectrodes for in-vivo determination of $\mathrm{pH}$. Electrochem. sensors, Biosens. their Biomed. Appl., Academic Press, Inc.; 2008, p. 261-305.

[76] Bandodkar AJ, Hung VWS, Jia W, Valdés-Ramírez G, Windmiller JR, Martinez AG, et al. Tattoo-based potentiometric ion-selective sensors for epidermal $\mathrm{pH}$ monitoring. Analyst 2013;138:123-8. doi:10.1039/c2an36422k.

[77] Cogan SF. Neural stimulation and recording electrodes. Annu Rev Biomed Eng 2008;10:275-309. doi:10.1146/annurev.bioeng.10.061807.160518.

[78] Meyer RD, Cogan SF, Nguyen TH, Rauh RD. Electrodeposited iridium oxide for neural stimulation and recording electrodes. IEEE Trans Neural Syst Rehabil Eng 2001;9:2-11.

[79] Venkatraman S, Hendricks J, King ZA, Sereno AJ, Richardson-Burns S, Martin D, et al. In vitro and in vivo evaluation of PEDOT microelectrodes for neural stimulation and recording. IEEE Trans Neural Syst Rehabil Eng 2011;19:307-16. doi:10.1109/ TNSRE.2011.2109399.

[80] Conway BE, Pell WG. Double-layer and pseudocapacitance types of electrochemical capacitors and their applications to the development of hybrid devices. J Solid State Electrochem 2003;7:637-44. doi:10.1007/s10008-003-0395-7. 
